\title{
Preparation and Evaluation of Candies from Citron Peel
}

\author{
Baber Shamrez ${ }^{1}$, Samra Aftab ${ }^{2}$, Muhammad Junaid ${ }^{3}$, Nazeer Ahmed ${ }^{4}$ and Saeed \\ Ahmed $^{5}$ \\ ${ }^{1}$ Food Science \& Technology Section, Agricultural Research Institute Tarnab, Peshawar-Pakistan \\ ${ }^{2}$ Agricultural Research Station Baffa, Mansehra-Pakistan \\ ${ }^{3}$ Research scientist Miscellaneous crops, Agricultural Research Institute Tarnab, Peshawar-Pakistan \\ ${ }^{4}$ Department of Entomology, The University of Agriculture, Peshawar-Pakistan, \\ ${ }^{5}$ Department of Horticulture, The University of Agriculture, Peshawar-Pakistan.
}

\begin{abstract}
Candy was prepared with 4 different combinations of $T_{o}$ (control), sliced citron peel $+30 \%$ sugar + Potassium metabisulphite, $T_{2}$ (Sliced citron peel $+40 \%$ sugar + Potassium metabisulphite and $T_{3}$ (sliced citron peel $+50 \%$ sugar + Potassium metabisulphite) To establish the best product, sensory evaluation was done on 9-point Hedonic scale. $T_{2}$ was found to be most preferred candy. These were assessed for organoleptic quality during storage at room temperature $\left(25-30^{\circ} \mathrm{C}\right)$ for 6 months. Candy can be preserved safely for 6 months in polythene bags.
\end{abstract}

Keywords: Citron peel, candy and sugar.

\section{Introduction}

Candy is a sweet food prepared from fruits or vegetables by impregnating them with sugar syrup followed by draining of excessive syrup and then drying the product to a shelf stable state. Fruits and vegetables like apples, ginger, mangoes, guava, carrot and citrus peels have been used to prepare candies (Mehta and Bajaj, 1984)

Citrus medica $L$., commonly known as citron is among the most important horticultural products belongs to the family Rutaceae and enjoyed universally. It has a great potential for value addition products. Citrus fruits are important due to nutritive, medicinal values and source of prosperity. In Pakistan, citrus is the largest group of fruits produced over an area of about 5 lac acres, which is about $40 \%$ of the total fruit produced in Pakistan. The production of Citrus fruit is more than 20 million ton (Agri. Stat. Pakistan, 2008-09). Citrus fruits, frozen concentrated orange juice and candies are in a great demand. In ancient times and in the middle Ages, the 'Citron' was employed as a remedy for seasickness, pulmonary troubles, intestinal ailments and other disorders.

Citron is a small tree, having large fruit $(20-22.5 \mathrm{~cm}$. long) resembling pineapple in shape. The most important part of the citron is the peel which is a fairly important article in international trade. After partial desalting and boiling to soften the peel, it is candied in a strong sucrose/glucose solution. The candied peel is sundried or put up in jars for future use. The candied peel is widely employed in the food industry, especially as an ingredient in fruit cake, plum pudding, buns, sweet rolls and candy. In Bangladesh, India, Indonesia, citron peel is eaten raw with rice. The entire fruit of the 'Fingered citron' is usually eaten (Z. Fleisher et al. 1991). In Guatemala, it is used as flavoring for carbonated soft-drinks. In Malaya, citron juice is used as a substitute for the juice of imported, expensive lemons (E. Nicolosi, et al. 2005). In Spain, syrup made from the peel is used to flavor unpalatable medical preparations (R. L. Luis, 2003). In India, the peel is a remedy for dysentery and is eaten to overcome halitosis (E. Isaac, 1959). C. medica is relevant to treatment of diabetes and Alzheimer's disease (C. Filomena, 2007). The candied peel is sold in China as a stomachic, stimulant, expectorant and tonic. In West Tropical Africa the citron is used only as a medicine, particularly against rheumatism. (Z. Fleisher, 1991). Srivastava et al. (2006) have recently developed jaggery based petha (Ash gourd) candy, which could be stored for 45 days under refrigerated condition.

Sulphites additives are used largely in the food industry as preservatives, anti browning agents and antioxidants. In many foods sulphites performs more than one function due to their versatile nature, cheap and easily availability (Taylor et al., 1986). Sugar provides energy and enhances the taste and texture of the food (Benitez et al., 2009). Thus studies were conducted to utilize the wasted citron peel for candies preparation, because of its great potential for value addition products as well as important due to nutritive and medicinal values.

\section{Materials And Methods}

The research was conducted to study the organoleptic changes occurring during the storage of citron candies at ambient conditions in the laboratory of Agricultural Research Institute Tarnab, Peshawar. Good 
quality, fresh Citrus medica were collected from the experimental field of Agricultural Research Institute Tarnab, Peshawar, Pakistan. Diseased free and fully ripe fruits were selected and washed to remove dust, dirt and any other foreign material. The fruits were cut into two halves and juice was extracted by using Rose Head machine and peel was washed and cutted into small slice shape.

\section{Preparation of Candies}

Sliced citron peels were blanched thrice for $2 / 5$ minutes in water at $170^{\circ} \mathrm{F}\left(76.7^{\circ} \mathrm{C}\right)$. Then peel turn into translucent, semisoft, and free from opaque spots. The pulpy centers are removed by hand and discarded, and the citrons are then preserved by gradually increasing the sugar content of the peel by immersion in a series of sugar syrups of increasing strength, over a period of three days. The product was then drained and kept in the dehydrator at a temperature of $60^{\circ} \mathrm{C}$ so as to dry it to the desired moisture level i.e $13-14 \%$. All the four treatments were dried in the same way. After drying these were packed in polythene bags.

\section{Treatments}

$\mathbf{T}_{\mathbf{0}}=$ Control

$\mathbf{T}_{1}=$ Sliced citron peel $+30 \%$ sugar + Potassium metabisulphite

$\mathbf{T}_{\mathbf{2}}=$ Sliced citron peel $+40 \%$ sugar + Potassium metabisulphite

$\mathbf{T}_{3}=$ Sliced citron peel $+50 \%$ sugar + Potassium metabisulphite

Storage

The samples were stored at ambient conditions for sensory evaluation after $0,30,60,90,120,150$ and 180 days. Sensory evaluation

The samples were evaluated by the panel of trained judges for color, flavor, texture and overall acceptability. Judges evaluated the samples using 9 point hedonic scale method as described by Larmond (1977) where 1 represents extremely disliked and 9 represent extremely liked.

\section{STATISTICAL ANALYSIS}

All the data regarding treatments and storage intervals was analyzed statistically by using Randomized Complete Block Design (RCBD) as recommended by Gomez \& Gomez (1984) and the means were divided by applying LSD Test at 5\% probability level as described by Steel and Torrie (1997).

\section{Organoleptic evaluation}

\section{Results And Discussion}

Citron peel candies were stored for a period of six months and were evaluated organoleptically for color, flavor, texture and overall acceptability at the storage interval of 30 days for a period of 180 days. The evaluation was carried out by using 9 points hedonic scale of Larmond (1977). The results obtained were summarized as:

\section{Color}

The mean score of judges for color were significantly $(p<0.05)$ decreased from 8.83 to 4.84 during storage (Table-1). For treatments maximum mean score was observed in sample $\mathrm{T}_{2}$ (7.86), while minimum mean score was recorded in sample $\mathrm{T}_{\mathrm{o}}(2.19)$.

Color of treatment $T_{2}$ was comparatively attractive during storage period at ambient temperature. Similar results have been reported by Durrani et. al. (2011) in development and quality evaluation of honey based carrot candy that osmotic drying had a protective effect upon the color and flavor of fully dried fruits.

Table I. Effect of storage period and treatments on color of citron peel candies stored at room temperature.

\begin{tabular}{|c|c|c|c|c|c|c|c|c|c|}
\hline \multirow{2}{*}{ Treatments } & \multicolumn{7}{|c|}{ Storage Intervals } & \multirow{2}{*}{$\%$ Decrease } & \multirow{2}{*}{ Mean } \\
\hline & Initial Day & 30 & 60 & 90 & 120 & 150 & 180 & & \\
\hline $\mathbf{T}_{0}$ & 8.33 & 2.00 & 1.00 & 1.00 & 1.00 & 1.00 & 1.00 & 88.00 & $2.19 \mathrm{~b}$ \\
\hline$T_{1}$ & 9.00 & 8.33 & 7.67 & 7.00 & 6.33 & 6.00 & 5.67 & 37.00 & $7.14 a$ \\
\hline $\mathbf{T}_{2}$ & 9.00 & 8.67 & 8.33 & 8.00 & 7.33 & 7.00 & 6.67 & 25.89 & $7.86 a$ \\
\hline $\mathbf{T}_{3}$ & 9.00 & 8.33 & 8.00 & 7.67 & 7.00 & 6.33 & 6.00 & 33.33 & $7.48 \mathrm{a}$ \\
\hline Mean & $8.83 a$ & $6.83 \mathrm{~b}$ & $6.25 b c$ & $5.92 \mathrm{bc}$ & $5.42 \mathrm{bc}$ & $5.08 \mathrm{c}$ & $4.84 \mathrm{c}$ & & \\
\hline
\end{tabular}

Flavor

Figures having different small letters are significantly different $(p<0.05)$.

Flavor is a vital quality factor that determines the consumer attraction to the product. The panelists clearly identified the changes in flavor profile of the samples rating the stored sample inferior as compared to the freshly prepared candies. The results pertaining to the response of flavor on the storage interval of the candies 
prepared from citron peel are presented in Table II. The mean score of judges for flavor significantly $(\mathrm{p}<0.05)$ decreased from 8.25 to 4.92 during storage. For treatments maximum mean score was recorded in sample $\mathrm{T}_{2}$ (8.05), while minimum mean score was observed in $\mathrm{T}_{\mathrm{o}}$ (1.71). Bhattacherjee et. al. (2012) reported similar results in quality evaluation of aonla candy and segments in syrup prepared from steep preserved fruits in water during storage.

Table II. Effect of storage period and treatments on flavor of citron peel candies stored at room temperature.

\begin{tabular}{|c|c|c|c|c|c|c|c|c|c|}
\hline \multirow{2}{*}{ Treatments } & \multicolumn{7}{|c|}{ Storage Intervals } & \multirow{2}{*}{$\%$ Decrease } & \multirow{2}{*}{ Mean } \\
\hline & Initial Day & 30 & 60 & 90 & 120 & 150 & 180 & & \\
\hline$T_{0}$ & 6.00 & 1.00 & 1.00 & 1.00 & 1.00 & 1.00 & 1.00 & 83.33 & $1.71 \mathrm{c}$ \\
\hline$T_{1}$ & 9.00 & 8.00 & 7.33 & 6.00 & 5.67 & 5.33 & 5.00 & 44.44 & $6.62 b$ \\
\hline $\mathbf{T}_{2}$ & 9.00 & 8.67 & 8.33 & 8.00 & 8.00 & 7.33 & 7.00 & 22.22 & $8.05 a$ \\
\hline$T_{3}$ & 9.00 & 8.00 & 7.67 & 7.33 & 7.00 & 7.00 & 6.67 & 25.89 & $7.52 \mathrm{a}$ \\
\hline Mean & $8.25 \mathrm{a}$ & $6.42 \mathrm{~b}$ & $6.08 b c$ & $5.58 \mathrm{bc}$ & $5.42 \mathrm{bc}$ & $5.17 \mathrm{c}$ & $4.92 \mathrm{c}$ & & \\
\hline
\end{tabular}

Texture

Figures having different small letters are significantly different $(p<0.05)$.

The mean score of judges for texture significantly $(\mathrm{p}<0.05)$ decreased from 9.00 to 5.25 during storage as presented in Table III. For treatments maximum mean score was observed in $\mathrm{T}_{2}(8.14)$, while minimum was recorded in $\mathrm{T}_{\mathrm{o}}$ (2.29). Similar results were observed by Muhammad et. al. (2007) during storage of pear glaces.

Table III. Effect of storage period and treatments on texture of citron peel candies stored at room temperature.

\begin{tabular}{|c|c|c|c|c|c|c|c|c|c|}
\hline \multirow{2}{*}{ Treatments } & \multicolumn{7}{|c|}{ Storage Intervals } & \multirow{2}{*}{ Decrease } & \multirow{2}{*}{ Mean } \\
\cline { 2 - 10 } & Initial Day & $\mathbf{3 0}$ & $\mathbf{6 0}$ & $\mathbf{9 0}$ & $\mathbf{1 2 0}$ & $\mathbf{1 5 0}$ & $\mathbf{1 8 0}$ & & \\
\hline $\mathbf{T}_{\mathbf{0}}$ & 9.00 & 2.00 & 1.00 & 1.00 & 1.00 & 1.00 & 1.00 & $\mathbf{8 9 . 0 0}$ & $\mathbf{2 . 2 9 b}$ \\
\hline $\mathbf{T}_{\mathbf{1}}$ & 9.00 & 8.33 & 8.00 & 7.33 & 7.00 & 6.67 & 6.00 & $\mathbf{3 3 . 3 3}$ & $\mathbf{7 . 4 8 a}$ \\
\hline $\mathbf{T}_{\mathbf{2}}$ & 9.00 & 9.00 & 8.67 & 8.33 & 8.00 & 7.00 & 7.00 & $\mathbf{2 2 . 2 2}$ & $\mathbf{8 . 1 4 a}$ \\
\hline $\mathbf{T}_{\mathbf{3}}$ & 9.00 & 8.67 & 8.33 & 8.00 & 8.00 & 7.33 & 7.00 & $\mathbf{2 2 . 2 2}$ & $\mathbf{8 . 0 5 a}$ \\
\hline Mean & $\mathbf{9 . 0 0 a}$ & $\mathbf{7 . 0 0 b}$ & $\mathbf{6 . 5 0 b}$ & $\mathbf{6 . 1 7 b}$ & $\mathbf{6 . 0 0 b}$ & $\mathbf{5 . 5 0 b}$ & $\mathbf{5 . 2 5 b}$ & & \\
\hline
\end{tabular}

Figures having different small letters are significantly different $(p<0.05)$.

\section{Overall acceptability}

The results pertaining to the response of the storage interval and treatment on overall acceptability are pertaining in Table IV. The mean score of judges for overall acceptability significantly $(\mathrm{p}<0.05)$ decreased from 8.70 to 5.00. for treatments maximum mean score was recorded in $T_{2}(8.02)$, while minimum mean score was observed in $T_{0}$ (2.06). Similar results were observed by Saini et. al. (1992) that osmotically dehydrated pear preserved with sugar and other preservatives retain maximum overall acceptability.

Table IV. Effect of storage period and treatments on overall acceptability of citron peel candies stored at room temperature.

\begin{tabular}{|c|c|c|c|c|c|c|c|c|c|}
\hline \multirow{2}{*}{ Treatments } & \multicolumn{7}{|c|}{ Storage Intervals } & \multirow{2}{*}{$\%$ Decrease } & \multirow{2}{*}{ Mean } \\
\hline & Initial Day & 30 & 60 & 90 & 120 & 150 & 180 & & \\
\hline$T_{0}$ & 7.78 & 1.67 & 1.00 & 1.00 & 1.00 & 1.00 & 1.00 & 87.14 & $2.06 \mathrm{~b}$ \\
\hline$T_{1}$ & 9.00 & 8.22 & 7.67 & 6.78 & 6.33 & 6.00 & 5.56 & 38.22 & 7.08a \\
\hline $\mathbf{T}_{2}$ & 9.00 & 8.78 & 8.44 & 8.11 & 7.78 & 7.11 & 6.89 & 23.44 & $8.02 a$ \\
\hline $\mathbf{T}_{3}$ & 9.00 & 8.33 & 8.00 & 7.67 & 7.33 & 6.89 & 6.56 & 27.11 & $7.68 \mathrm{a}$ \\
\hline Mean & $8.70 \mathrm{a}$ & $6.75 a$ & $6.28 \mathrm{bc}$ & $5.89 \mathrm{bc}$ & $5.61 b c$ & $5.25 b c$ & $5.00 \mathrm{c}$ & & \\
\hline
\end{tabular}

Figures having different small letters are significantly different $(p<0.05)$.

\section{Conclusion}

From the present study it can be concluded that the candy prepared from $40^{\circ}$ brix solution $\left(\mathbf{T}_{2}\right)$ is best for commercialization purpose. 


\section{Literature Cited}

[1]. Agri. Stat. Pakistan. 2008-2009. Agricultural Statistic of Pak. Govt. of Pakistan. Ministry of Food, Agri. and Livestock (Economic Wing) Islamabad, Pak: 34-55.

[2]. AOAC. 2000. Official Methods of Analysis. The Association of Official Analytical Chemists, $17^{\text {th }}$ Edn. Chap. 17.

[3]. Benitez, E. I., D. B. Genovese and J. E. Lozano. 2009. Effect of typical sugars on the viscosity and colloidal stability of apple juice. Food Hydro. 23: $519-525$.

[4]. Bhattacherjee, A. K., A. Dikshit, S. Lumar and D. K. Tandon. 2012. Quality evaluation of aonla candy and segments in syrup prepared from steep preserved fruits in water. Indian J. Natural Prod. \& Resources. 4(1): 119-122.

[5]. Durrani, A. M., P. K. Srivastava and S. Verma. 2011. Development and quality evaluation of honey based carrot candy. J Food Sci Tech. 48(4):502-505.

[6]. Filomena, C., A. S. Giancarlo, T. Rosa, R. L. Monica, and M. Francesco. 2007. Phytotherapy Res. 21 (5), 427.

[7]. Fleisher, Z. and A. Fleisher. 1991. J. Essent. Oil Res. 3 (5), 377

[8]. Gomez, K.A and A. A Gomaz. 1984. Statistical procedure for Agri. Res. 2nd Edn. 8-22.

[9]. Isaac, E. 1959. Economic Geography 35 (1), 71.

[10]. Larmond, E. 1977. Laboratory methods of sensory evaluation of foods. Canada. Deptt. Agric. Pub. No.1284. pp. 36 - 37.

[11]. Luis, R. L. 2003. Economic Botany 57 (4), 502.

[12]. Mehta. U., S. Bajaj. 1984. Changes in the chemical composition and organoleptic quality of citrus peel candy during preparation and storage. J Food Sci Technol 21:422-424

[13]. Muhammad, N., A. S. Shah, A. Riaz, M. M. Hashim, Z. Mahmood and M. S. Hashmi. 2007. Prepration and evaluation of pear glace at different stages of maturity. Sarhad J. Agric. 23(2):305-308.

[14]. Nicolosi, E., L. M. Stefano, E. O. Mohamed, N. Moshe, and E. G. Eliezer. 2005. Hort. Sci. 40 (7), 1963.

[15]. Saini, S., D. S. Sogi and A. S. Bawat. 1992. Shelf studies on osmotically dehydrated pear preserved by sugar. J. Food Sci. Tech. Maysore. 60(2): 230-232.

[16]. Srivastava AK, Singh OP, Srivastava PK (2006) Development of jaggery based petha (ash gourd) candy, its quality evaluation and study on stability under ambient and refrigerated storage. Bev. Food World 33:71-73

[17]. Steel, R. G. D. and J. H. Torrie. 1997. Principles and procedures of statistics. M. C. Graw Hill Pub. Comp. Inc. New York.

[18]. Taylor, S. L., N. A. Higley and R. K. Bush. 1986. Sulfates in foods: uses, analytical methods, residues, fate, exposure, assessment, metabolism, toxicity and hypersensitivity. Advances in Food Res. 30: 25-31. 